well be understood. Nevertheless, a clearer indication of the relative value of various methods of treatment would have been desirable, rather than the traditional method of offering a choice of methods any of which ' may be employed'.

There is no doubt this book will retain its position as the standard text of British neurology for many years to come.

\section{A Medical Greek and Latin Workbook}

James A. McCulloch, PH.D. Pp. I 54. Springfield, Illinois: Charles C. Thomas. 1962. $\$ 5.75$.

All serious students of the history of medicine are aware that from the earliest times the teaching of the art of medicine was in the hands of the Church, many of the celebrated physicians being men in Holy Orders, who were also classical scholars. Moreover, some of the most important treatises (one may cite for example the publications of the immortal Harvey), were written by their authors in Latin, a knowledge of which was indispensable to the physicians of the day. It is remarkable how many of the leading clinical teachers in the nineteenth century were classical scholars of our two ancient Universities: their liberal education gave them much of that holistic outlook, so greatly needed in medical practice today, and receiving, alas, little more than lipservice. In medicine, no less than in other branches of study, there is no doubt that a preliminary grounding in the classics is a great asset. For the average medical student, however, it is hard to come by: the present curriculum demands so much more training in technology than formerly. Considerations of time and finance alike constitute an obstacle to the pursuit of general knowledge such as was not experienced to the same extent half a century ago.

Dr. McCulloch's workbook is hardly a substitute for the systematic study of Greek and Latin literature: in fairness it must be said that he does not claim that it is. It does, however, give students an opportunity to learn something of the etymology of the numerous words with which during their course they must become acquainted. From this volume they may well find a greater facility in memorizing these strange new words. They may also gain a greater interest and a finer appreciation of the meaning and significance of what they read in their text-books and hear in their lectures.

This book is an original and painstaking experiment upon which its author is to be congratulated. We wish it every success.

\section{An Atlas of Positive Contrast Myelography}

JAMES Bull, M.A., M.D., F.R.C.P., F.F.R., and WYLIE McKISSOCK, O.B.E., M.S., F.R.C.S. Pp. vii +47 , illustrated. Oxford, New York, London and Paris: Pergamon Press. 1962. 84s.

A title page bearing the names of Dr. James Bull and Mr. Wylie McKissock gives promise of a work of authority and great merit and this small volume does not disappoint the reader. The use of myelography as an aid to diagnosis of lesions of the spine has spread beyond the more specialized neuro-surgical centres and in more peripheral hospitals this investigation is being undertaken with increasing frequency. A well-illustrated. book giving the essential facts about positive contras myelography is therefore welcome.

A brief historical survey precedes an excellent descripe tion of the radiological anatomy of the spinal cord and there is a clear line drawing to illustrate this. Th technique of myelography is described with reference both to the lumbar and cisternal routes. The description is in sufficient detail to enable the reader to undertake the investigation with confidence.

There is a short section to describe and illustrate th $\vec{\sigma}$ normal myelographic findings in the different regionsand projections. Three illustrations show some of the artefacts which may be encountered.

The main part of the book describes spinal tumours under the three headings extradural, intrathecal and intramedullary. Short case histories are provided with. the illustrations and in each case the operative and pathological findings are included. The final section deals with miscellaneous lesions, such as vasculat tumours, the Arnold Chiari malformation, arachnoiditis and cysts of the spinal canal.

The quality of the illustrations which form the majo? feature of this book is extremely high and the authors and their publishers are to be congratulated on the excellent reproduction of detail. A number of line drawings are also included to aid in the interpretation of the radiographs.

This book can be recommended to all postgraduate students of radiology, neurology and neuro-surgery.

Towards a Clearer View-The Organisation Diagnostic X-ray Departments

Pp. xix + 126, illustrated. Published for the Nuffield Provincial Hospital Trust by Oxfor University Press. 1962. 7s. 6d.

This is the report of an investigating team who spen a total of 18 weeks in the diagnostic X-ray departments of six representative hospitals in Great Britain.

In the 18 weeks of observation the team encountered practically all difficulties that may beset a radiologicab department. This is cold comfort to those of us trying to cope with these difficulties in our own departmentsevery day, but it shows that we are not alone in ou? problems.

Based on their findings, the team make numerousं suggestions for improving the organization of radiologi 3 . cal departments. This is by far the most valuable pari of the report and should be compulsory reading for alf radiologists and superintendent radiographers. $\mathrm{Ob}-$ viously all these suggestions are not applicable to every? department but there are so many good suggestions that no one can fail to benefit from a thorough study of themb

What is obvious from this report is that much more money will have to be spent initially to make depart $N$ ments more efficient. In the long view this will result in overall saving, better service to the patient and improved working conditions for the staff. 